\title{
Developing future nurse educators through peer mentoring
}

This article was published in the following Dove Press journal:

Nursing: Research and Reviews

9 January 2015

Number of times this article has been viewed

\section{Patricia A Rosenau \\ Rita F Lisella \\ Tracey L Clancy \\ Lorelli S Nowell}

Faculty of Nursing, University of Calgary, Calgary, AB, Canada
Correspondence: Patricia A Rosenau Faculty of Nursing, University of Calgary, 2500 University Drive NW, Calgary, AB, Canada T2L IN4

Tel +l 4032107343

Fax + I 4032109637

Email prosenau@ucalgary.ca
Background: The nursing workforce and nursing education demographic trends reinforce the urgency to cultivate future nursing leaders, educators, and mentors. The changing realities of health care environments, involving crowded student placements, overtaxed clinical mentors and preceptors, and inexperienced staff, hamper student learning and professional development. Peer mentoring has been used successfully in nursing education to enhance student engagement and the quality of the student learning experience. Although various terms like peer mentor have been used to describe the role of senior students facilitating junior student learning, the literature is silent about how peer mentoring fosters the development of future nursing education leaders.

Objectives: The aim of this study was to understand how peer mentorship fosters the development of nursing education leadership in senior undergraduate nursing students enrolled in an elective undergraduate peer-mentoring credit course, Introductory Concepts in Nursing Education and Leadership Through Peer-Led Learning.

Design and method: This phenomenological study explored the development of nursing education leadership in senior undergraduate students through the analysis of critical reflections of individual senior students and online discussions between triads of senior students teaching/ learning across diverse junior-level theory and practice courses.

Participants: Seventeen senior undergraduate nursing students enrolled in the elective course participated in the study.

Results: From the critical reflections and online discussions, four themes emerged: "developing teaching philosophies and pedagogies", "learning teaching strategies", "supportive peer relationship", and "benefits of the peer mentorship program".

Conclusion: The creation and promotion of peer leadership opportunities provide peer-to-peer learning opportunities and increase leadership and teaching skills of senior nursing students. In the long term, successful peer leadership programs have the potential to benefit individuals outside of the mentorship relationship including peer leaders' future peers and coworkers, their clients or patients, and eventually their own students as they become nurse educators of the future.

Keywords: nursing education, peer mentorship, qualitative study, nursing students

\section{Introduction}

The nursing workforce and nursing education demographic trends ${ }^{1}$ reinforce the urgency to cultivate future nursing leaders, educators, and mentors. In Canada, the nursing labor force trends point to a profession under great strain with a steadily climbing population of nurses approaching retirement age, the proportion of registered nurses (RNs) aged 60 or older matching the proportion under age 30, and a slower overall workforce growth rate. ${ }^{2}$ Considering these problematic trends and the significant 
numbers of Canadian RNs leaving the workforce over the next few years, ${ }^{3}$ of which many are educators, the need to develop nursing leaders and educators is critical.

In concert with the demographic nursing trends are the changing employer expectations of nurse graduates. In today's health care environment, there are many factors that inhibit the provision of appropriate clinical mentorship/preceptorship, which, in turn, influence student clinical learning and professional development. Some of the realities include heavy nurse workloads involving increased levels of acuity and rapid patient turnover combined with inadequate staffing levels, staff inexperience and perceived lack of support for role development, minimal resources for professional development, staff misconceptions, and overcrowded placements. ${ }^{4}$ Additionally, common student concerns with clinical practice include poor role modeling, inadequate and irregular clinical supervision resulting in feelings of isolation and anxiety, ${ }^{5}$ the view that theory is not applied to practice, and that learning frequently occurs by trial and error. ${ }^{4}$ There is an urgent need to enhance the quality of student learning experiences by nurturing professional skill development in supportive environments that portray realities and link theory to practice.

One mechanism to address student needs for the current health care context is to have students assume leadership roles for the purpose of facilitating the knowledge and experience of their junior peers. ${ }^{6}$ The multiple needs at the system and educational levels prompted the creation of an innovative, student-centered, inquiry- and experiential-based peer-mentoring course. This paper describes the design and evaluation of this elective course, which aimed to understand how peer mentorship fosters the development of nursing education leadership in senior undergraduate students.

This course was framed by Kolb and Kolb's ${ }^{7}$ cycle of experiential learning whereby social knowledge is created and recreated in the personal knowledge of the learner. The overall goal of developing a peer-mentoring initiative has relevance to promoting leadership and pedagogical knowledge acquisition, skills, and critical-thinking abilities as one mechanism to cultivate future leaders, educators, preceptors, and mentors in nursing.

\section{Background}

The literature supports basic nursing skill acquisition in a safe environment that emphasizes practice and feedback. ${ }^{8}$ It is within this context of foundational nursing practice that senior undergraduate students, with grounded foundational nursing skills, clinical course experiences, and recent, experiential knowledge of first-year nursing student challenges, can facilitate junior undergraduate nursing students' integration of theoretical knowledge to practice and help to encourage practice reflection in nonthreatening ways. ${ }^{5}$

Senior undergraduate students benefit as early mentorship skills are utilized, ${ }^{9}$ and students continue to refine their communication, problem-solving, analytical, and critical-thinking skills. Roberts ${ }^{10}$ found that the peers acted as resources to pass on survival skills and help junior peers to learn how to be a nurse. As students build a repertoire of teaching strategies and experiences, creativity is fostered as well as a clearer understanding of their own learning processes. ${ }^{11}$ The co-teaching approach with an educator promotes professional responsibility, stimulates the senior student's reflective thinking processes, enhances confidence and competence, and aids in the transition from student to qualified nurse. ${ }^{9}$

Incorporating students as supplementary teaching support mechanisms within higher education programs has been established and recognized worldwide as a valuable strategy shown to positively influence cognition and affect on both the peer leaders and the students taught. ${ }^{12}$ Additionally, the academic gains associated with formalized peer leadership are equal to or greater than some of the conventional procedures involving lecture and student discussion. ${ }^{13}$ It is also important to recognize that preparing students for complex job responsibilities and leadership in society is a major role of universities. These values are strengthened by peer leadership roles because they actively support student involvement through the undergraduate experience and encourage student academic success.

Peer mentoring has been used in a variety of ways in nursing education. Bensfield et $\mathrm{al}^{6}$ described a peer mentorship program where clinical faculty, peer leaders, and laboratory faculty worked together to facilitate the learning of sophomore nursing students. Junior and senior students served as peer leaders while observing, coaching, and reinforcing the learning of sophomore students in a fundamental nursing laboratory course. Becker and Neuwirth ${ }^{14}$ documented a study involving senior-level nursing students as teaching assistants for beginning students in the clinical setting. The senior students were assigned to help junior-level faculty on a general surgical floor, work in the skills laboratory to help junior-level students with skill practice, and tutor junior-level students who may be experiencing classroom challenges. Owens and Walden ${ }^{5}$ described a peer-mentoring strategy within a skills laboratory for junior nursing students where senior nursing students served as peer mentors and provided additional skill practice time, assisted students requiring 
skills remediation, and assisted instructors in preparing for skills testing. The primary aim of the peer-mentoring strategy was to decrease the anxiety experienced by students during skills testing. A nonexperimental design was used to evaluate the effectiveness of this teaching strategy, and the mean response over the 3-year evaluation period indicated that students perceived peer instruction to be beneficial in decreasing their anxiety associated with psychomotor testing. Peer mentoring has been used to provide a network of support from peers and higher level students who serve as mentors to students at lower academic levels through assisting students with skill practice and critical thinking, and supporting an open and comfortable learning environment. ${ }^{15}$ Peer mentors educate, guide, coach, support, counsel, and serve as role models for fellow students. ${ }^{15}$ Sweet and Fusner described a peer-mentoring program where senior students have to guide new students toward positive direction, support and challenge through the transition to higher education, and ease the social integration of students so that they perceive that they are valued members of the class. ${ }^{16}$

Peer mentoring is one way to teach students the value of collegiality, leadership, and behaviors that develop collaboration in the workplace. ${ }^{17}$ Teaching approaches, such as incorporating peer mentoring, can infuse excitement in the educational process, help meet the learning needs of various levels of students, and possibly build stronger collegial relationships for the future. ${ }^{18}$ If students learn to practice mutual respect, peer nurturing, and co-learning, they emerge better equipped to survive and better able to change the reality of nursing in the workplace today. ${ }^{17}$ Although various terms like peer mentoring are used to describe how senior students help junior students learn, the educational model supporting the role is ambiguous in the nursing education literature.

Although peer mentoring has been used in nursing education, there is a gap in literature that identifies how peer mentoring fosters the development of future nursing education leaders. Leadership competency is developed in the student through creating dynamic teaching and learning environments that encourage self-reflection, clinical judgment, open dialogue, peer feedback, and role modeling. ${ }^{19}$ The positive outcomes of this learning environment provide the students with the necessary foundation to lead innovation and change in practice, and develop their roles. For the purpose of this paper, peer mentorship is defined as senior students facilitating junior students' learning and development of knowledge, and working through and with others to foster the development of nursing education leadership.

\section{Experiential learning theory}

Kolb's ${ }^{20}$ cycle of experiential learning defines learning as the "process whereby knowledge is created through the transformation of experience" ( $p$ 41). The learning cycle encompasses four learning modes: concrete experience, abstract conceptualization, reflective observation, and active experimentation. The learner experiences a four-stage recursive cycle of learning, in which immediate or concrete experiences provide a basis for observations and reflection. These observations and reflections are translated into abstract concepts producing new implications for action, which can be actively tested, thus creating new experiences.

Kolb's ${ }^{20}$ cycle of experiential learning formed the foundation of the course development whereby the senior student gains an understanding of the abstract concepts of teaching and learning and then applies them in co-teaching experience in a classroom context. The subsequent reflection of the experience is translated into further action and experimentation in the classroom setting. Kolb and Kolb ${ }^{7}$ state that "all learning is relearning" facilitated through a process that draws out the students' beliefs about a topic so that they can be examined, tested, and integrated with new, refined ideas ( $\mathrm{p}$ 194). The process of learning is enhanced by the movement, back and forth, between reflection and action, and feeling and thinking.

\section{Course development}

The Introductory Concepts in Nursing Education and Leadership Through Peer-Led Learning course was created in response to the need to cultivate future nursing leaders, educators, and mentors. Drawing from Kolb's ${ }^{20}$ cycle of experiential learning, the elective course incorporates a unique nursing education teaching and learning process in the application of nursing education pedagogy. The 13-week course framework aims to promote senior undergraduate nursing students' leadership and pedagogical knowledge acquisition, skills, and critical-thinking abilities for the purpose of facilitating the nursing practice knowledge and experience of their junior peers who are first-year nursing students enrolled in nursing theory or foundational skills courses. The course provides an opportunity to explore the learning experiences of peer leaders through various paired, group, and individual written, verbal, and online assignments. The senior students taught theory and foundation skills, under the guidance of a junior course host instructor, to junior students three times for 3 hours each, for a total of 9 hours over the 13-week semester. Content of the lessons included mobilization, catheterization, professional communication, oxygenation, and personal care (Figure 1). 


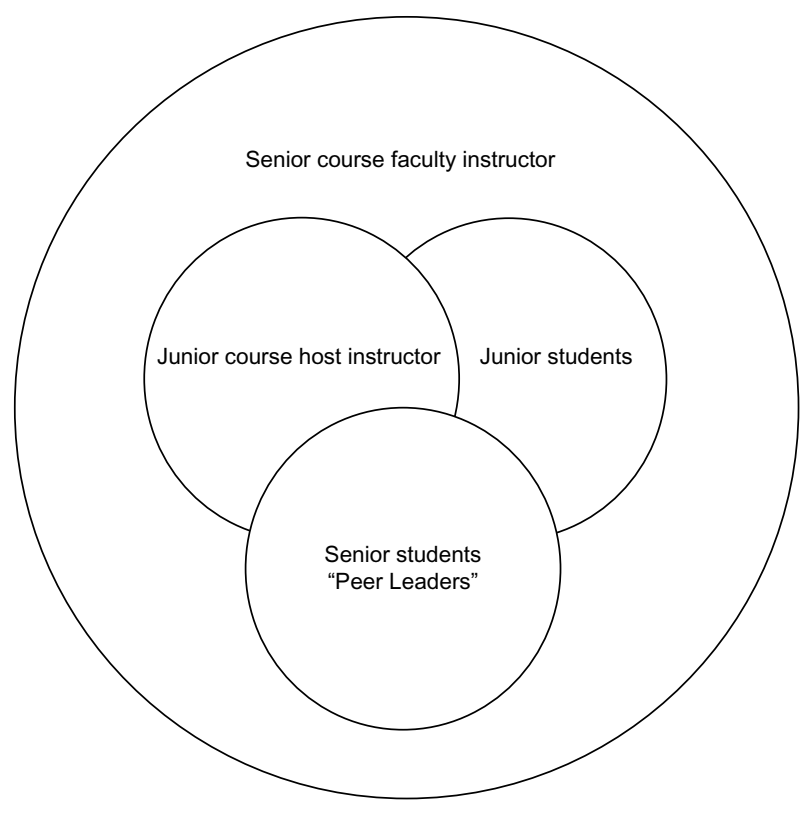

Figure I Course model: Introductory Concepts in Nursing Education and Leadership Through Peer-Led Learning.

Students engaged in critical reflection, challenging their presuppositions and assessing their knowledge, understanding, and beliefs relative to their teaching, learning, and mentoring experiences. The critical reflections of individual peer leaders, and online discussions between triads of peer leaders teaching/learning across diverse junior-level theory and practice courses, capture rich insights about the learners' understanding of nursing leadership and pedagogical knowledge acquisition, skills, and critical-thinking abilities. No other educational research has studied these elements of co-teaching and co-learning within the context of a similar course model. The role descriptions of the senior course faculty instructors, junior course host instructors, and senior and junior undergraduate students can be found in Table 1.

\section{Purpose}

As part of a larger course evaluation, the aim of this study was to understand how peer mentorship fosters the development of nursing education leadership in senior undergraduate students.

\section{Methodology}

Phenomenology was used to research the lived experience of senior undergraduate nursing students mentoring junior peers. Based on the philosophy of Husserl, ${ }^{21}$ the phenomenological method of inquiry emphasizes the rigorous and unbiased study of things as they appear to arrive at a description and pure understanding of the human experience..$^{22,23}$

\section{Sample}

Following approval from the local research ethics board of the University of Calgary (AB, Canada), fourth-year

Table I Role descriptions

\begin{tabular}{|c|c|}
\hline Person & Role \\
\hline Senior course faculty instructors & $\begin{array}{l}\text { Plan, facilitate, and guide peer leader knowledge application and synthesis about evidence-informed nursing } \\
\text { education pedagogies, learning styles, teaching and learning principles, and teaching strategies } \\
\text { Pair peer leaders, match them with a host instructor, and facilitate team-building strategies between the host } \\
\text { instructor and paired peer leader triad } \\
\text { Evaluate peer leader learning based on various paired, group, and individual written, verbal, and online assignments } \\
\text { addressing course learner outcomes }\end{array}$ \\
\hline Junior course host instructors & $\begin{array}{l}\text { Teaching the theory and foundation skills course } \\
\text { Role model and mentor to peer leaders } \\
\text { Develop a working relationship plan with their peer leaders considering their roles and learning styles, and outlining } \\
\text { mutual expectations and goals, communication processes, and timelines } \\
\text { Encourage, support, and provide feedback to peer leaders regarding their teaching, lesson plans, professionalism, } \\
\text { and attitude }\end{array}$ \\
\hline $\begin{array}{l}\text { Peer leaders (senior } \\
\text { undergraduate nursing students) }\end{array}$ & $\begin{array}{l}\text { Met preestablished criteria and approval from the course instructor prior to registering for the course } \\
\text { Complete paired, group, and individual written, verbal, and online assignments } \\
\text { Facilitate the nursing practice knowledge and experience of their junior peers who are first-year nursing } \\
\text { students enrolled in nursing theory or foundational skills courses } \\
\text { With the faculty mentor, progress through a co-teaching approach and mentorship process promoting } \\
\text { professional responsibility, building collaborative working relationships, stimulating reflective-thinking processes, } \\
\text { and enhancing confidence and competence }\end{array}$ \\
\hline $\begin{array}{l}\text { Junior undergraduate } \\
\text { nursing students }\end{array}$ & $\begin{array}{l}\text { Attend weekly classes where the peer leaders and junior course faculty mentors were directly involved in } \\
\text { teaching in the nursing laboratory } \\
\text { Attend open peer-assisted learning sessions to practice skills with the support of the peer mentors } \\
\text { Provide written feedback to the peer mentors }\end{array}$ \\
\hline
\end{tabular}


undergraduate nursing students in a western Canadian university who were enrolled in the Introductory Concepts in Nursing Education and Leadership Through Peer-Led Learning course were invited to participate in the study. Participants were informed that participation was voluntary, and informed consent was obtained. Participants were made aware that their assignments would be secure. All 17 students enrolled in the course consented to participate. Participants consisted of 15 female and two male senior undergraduate nursing students.

\section{Data collection}

Data were collected in the form of 17 critical reflections and 15 online discussions. Both critical reflections and online discussions were captured in the final weeks of the course. The critical reflection assignment provided the peer leaders with an opportunity to articulate what constituted their professional teaching practice by reflecting on the experience as a peer leader following their individual teaching experiences. Within the critical reflections, peer leaders identified how they would "lead self into the future" by identifying the meaning and relevance of their professional teaching practice, career plans, and goals, and what they need to learn further, and how to accomplish this. The online discussion board was used to develop a learning community where the peer leaders introduced each other to their initial thoughts, values, beliefs, and observations related to the teaching and learning dynamic that they experienced. On an ongoing basis, the peers responded to each by posting questions, insights, and comments that stimulated or challenged their thinking.

\section{Data analysis}

Data were analyzed in accordance with the seven-step phenomenological method outlined by Colaizzi. ${ }^{24}$ To establish authenticity and trustworthiness of the research, and ensure that the line of thinking and interpretation was clear to the readers and true to the data, the researchers cross-checked the analysis during each step of this procedural process:

1. The critical reflections and online discussions were read repeatedly to gain an understanding of the participant's experiences and to develop sensitivity for the feelings and attitudes described by the participants.

2. After reviewing each critical reflection and online discussion, data were hand coded, and significant statements were extracted. These statements were highlighted and then cut from the appropriate transcript and pasted into a separate document while retaining the transcript, page, and line numbers. For every significant statement extracted, meanings were formulated based about the participant's narratives. As formulated meanings were developed, the transcripts were read again to confirm that the contextual meaning was not lost.

3. The formulated meanings were arranged into theme clusters and then into emergent themes. Auditability was maintained through an audit trail of theme clusters with associated significant statements.

4. Emergent themes, theme clusters, and formulated meanings were incorporated into a description to create the overall structure that contains all of the elements of the experience of the senior students.

5. Findings were confirmed with the study participants to ensure the validation and extend the rigor of interpretation in this study.

6. Any new relevant data acquired from the participant's validation were incorporated into the final description.

\section{Findings}

From the critical reflections and online discussions, four comprehensive themes emerged: benefits of the peer mentorship program, developing teaching philosophies and pedagogies, learning teaching strategies, and supportive peer relationships. Each theme is explored and supported with integration of quotations from the transcribed interviews.

\section{Benefits of the peer mentorship program}

The senior nursing students chose to enroll in the elective course for a variety of reasons. Some students articulated that they had a passion for teaching and wanted to teach in the future.

I also have always hoped to be a nursing instructor [...] this course had provided me with a foundational skill set to accomplish this goal and to flourish as an educator. Overall, this experience has been invaluable, making me excited and proud about becoming a nurse as well as inspiring me to continue my learning, to teach others, and to lead others throughout my career.

Other students chose to become peer mentors to give back by being a positive role model to first-year nursing students, to help decrease first-year nursing students' anxiety, and to create a supportive learning environment.

All through my first year I wished that I had had an older student to act as a resource and sounding board for me, to answer my questions and provide encouragement. I feel privileged to be in that position for these students. 
The students described numerous benefits of peer mentorship including developing an increased awareness of their own values and beliefs as people and professional nurses. Many of the students expressed an increase in confidence, maturity, and responsibility. One of the students expressed her growth as a leader and professional:

This has been a tremendously valuable experience, and has made me stronger as a person, a leader, and a professional. As a person, I am more confident in my abilities to connect with others. As a leader, I am more inclined to help others discover their strengths to be leaders themselves. Lastly, as a professional, I feel more aware and accountable to the needs of those around me.

They also developed a heightened awareness of the roles and responsibilities of nursing educators through the development of foundational teaching skills. One of the students expressed the skills and knowledge she gained through the course:

I have gained a large amount of knowledge to help me work towards being the best I can be in regards to my nursing career. With this experience I have a stronger foundation on which to build my possible teaching career in a positive manner. I will use my experience to learn how to lead others in my practice, being more cognizant of different learners and different methods of doing things. I can more readily understand my colleagues and help guide them in a constructive manner as I have been doing with the first year nursing students.

Students developed insight into how to integrate teaching as a part of their professional career development. They expressed that they had gained important skills that they could incorporate into all aspects of their future nursing careers including public speaking, leadership, collegial teaching, listening skills, communication skills, patience, collaboration, seeking feedback, and an increased consciousness of how to approach and teach patients.

\section{Developing teaching philosophies and pedagogies}

Through dialoguing with peers, drawing on previous experiences as a student, and using teaching frameworks, students were able to begin to develop and understand their teaching philosophy and pedagogy. This was described by one student:

Through classroom and online discussion, literature, class lectures, and direct teaching experience, I have been given the chance to form a unique teaching philosophy. My teaching philosophy, as defined by my values and beliefs and favored teaching pedagogy, will continue to guide me in my future teaching opportunities and nursing practice.

Another student wrote:

Pulling together my values and beliefs of teaching has allowed me to start to develop a unique teaching philosophy, which shapes how I teach, the strategies I use, and my attitude towards teaching and learning.

As the students gained teaching experience, they began to learn from their mistakes and establish flexible pedagogical approaches for changing situations.

My initial pedagogy consisted mainly of conventional methods of teaching. Yet by learning from mistakes, observing my faculty mentor and partner peer leader, becoming informed through literature as well including tips my peers have posted on the discussion board, my values and beliefs regarding teaching had evolved to a pedagogy that consists of a combination of convention, critical and phenomenological flavors.

Students were supported in their exploration of current literature while reviewing the core concepts of various pedagogies, and developing greater understanding of various types of learners to advance their pedagogical knowledge.

\section{Learning teaching strategies}

Senior students were encouraged to explore a variety of teaching strategies aimed to create a learning environment that was trusting, supportive, dynamic, respectful, fun, and nonjudgmental. One of the students reflected on using storytelling as a teaching strategy:

I have seen throughout this entire experience how useful stories can be in teaching, and how they not only promote intense reflection and dialogue but also how they inadvertently assist students in developing critical thinking skill.

Other teaching strategies explored by the students included the use of humor, games, reflective questioning, narratives, evoking emotional responses, connecting to life experiences, group work, scenarios, and silence.

Through the experience of teaching junior nursing students, senior students developed a greater understanding of the skills and knowledge required to become an effective educator. One student wrote:

Teaching is really an art and takes a lot of practice and reflection to master. Being a peer leader has given me a 
greater appreciation for the work of a teacher, but I can still relate to what the students are going through. Hopefully, I can keep this perspective and be more understanding of my nursing peers, patients, and students that I work with in the future.

The senior students were also able to co-teach with a peer, and this was viewed as a beneficial experience where:

[...] you can both challenge and support one another [...] when we are working as nurses, we can engage in 'peer coaching' to share knowledge with our colleagues and to offer feedback on each other's performance of a new skill.

The lived experience of being a student in the course allowed students to explore various teaching strategies and cultivate a greater understanding of the complexities of teaching while supporting one another in their teaching practice. The supportive relationships that developed between the peers also played a role in their development.

\section{Supportive peer relationships}

The relationships among the senior students were supported through the use of an online discussion board. This tool provided the students with support, feedback, and suggestions to enhance their teaching practice. One student wrote about the discussion board being:

[...] important in terms of debriefing and asking for suggestions on how to plan my lab as well as seek validation of my teaching methods.

The discussion board also:

[...] became a point of reflection as the narratives that other students offered gave me further insight into variations among different pedagogies [...] my teaching philosophy became stronger and more encompassing as I looked for feedback from other students.

The online discussion board opened conversations about similar challenges, provided a platform to analyze teaching practice, and enhanced opportunities to ask questions to stimulate thinking and evoke responses. Using online discussion boards, students were able to draw attention to pertinent and relevant literature to broaden the understanding of various teaching philosophies and pedagogies.

\section{Discussion}

This phenomenological study revealed that engaging in the peer mentorship course had many benefits for the senior students. The students gained an increased passion for learning, further developed awareness of their own values, and began to integrate teaching into part of their professional practice. They were able to explore, develop, and understand their own teaching philosophies and pedagogies. Through engaging in a variety of teaching strategies, the students gained a greater appreciation of the skills and knowledge required to be an effective educator. As the supportive peer relationships developed, the students were able to reflect on their experiences while providing support and feedback to each other.

The students in this study described various benefits of the peer mentorship course including developing an increase in confidence, maturity, and responsibility as well as developing an increased awareness of their own values and beliefs as people and professional nurses. These findings add to previously identified benefits of peer mentoring in the literature including improvements to self-confidence, personal and professional growth, cooperative learning and critical thinking, leadership skills, and interpersonal and communication skills, as well as reduced anxiety. ${ }^{6,25,26}$

Through exploring current literature and dialoguing with peers, the students were able to begin to develop and understand their own teaching philosophy and pedagogy. Kohler-Evans ${ }^{27}$ argued that peer mentorship supports the development of professionals who collaborate, problem solve, share resources and perspectives, and conceptualize teaching as a process of learning. When two teachers teach the same subject matter to similar students, they can compare the effectiveness of different strategies and methods of teaching, and they engage in pedagogical discussions that rise above the particularities of a single lesson. ${ }^{27}$

The experience of teaching and co-learning provided an opportunity for the senior students in this inquiry to develop a greater understanding of the skills and knowledge required to become an effective peer mentor and educator. Co-teaching was identified by Chandler ${ }^{28}$ and Tobin and Roth ${ }^{29}$ as a way of creating new opportunities to do the following: collaborate; build student teachers' sense of accomplishment; yield a broader range of insights, ideas, and talents; and allow the co-teachers to more effectively meet individual learning needs within the classroom. The interaction among coteachers taps into each participant's creativity ${ }^{30}$ and by sharing and distributing intellect, roles, and responsibilities between co-teachers, there are more resources for learning and more possibilities for engagement in the classroom..$^{25,28}$

The relationships among the senior students in this inquiry were supported through the use of an online discussion board. Sims-Giddens et $\mathrm{al}^{26}$ suggested that peer mentoring allows 
partners to draw upon each other's individual knowledge, skills, insights, and approaches and to learn from each other's styles and differences. Through observation and dialogue with an equal-status peer, peer mentors are able to clarify, reflect upon, and construct meaning from their experiences. They are able to share ideas, resources, and talent while building upon and expanding each other's understandings and enhancing each other's ability. ${ }^{25}$ Collegiality was developed among the students in this study as they took the time to support and listen to one another and engage in dialogue about their experiences to facilitate a broader understanding of nursing leadership and pedagogical knowledge.

This research study is limited in that it is based upon insight from 17 informants from one specific institution and focused only on the experiences of the senior students. Additionally, the participants were a homogeneous sample that limits the generalizability of the results. Research aimed at gathering data from a larger number of senior students, faculty members, and junior students from a variety of educational institutions over a longer period of time as they transition into professional practice would result in an increased amount of relevant and informative data and provide greater insight into the lived experience of those involved in a peer mentorship program. Moreover, the longitudinal benefit of incorporating a peer mentorship course into the undergraduate curriculum is another potential area for future research. In light of these limitations, this study provides preliminary evidence-based knowledge to support the continued integration of the Introductory Concepts in Nursing Education and Leadership Through Peer-Led Learning course in our undergraduate nursing curriculum.

\section{Conclusion}

This study provides support for the implementation of educational leadership opportunities for senior undergraduate nursing students. The creation and promotion of peer mentorship within undergraduate nursing curriculums provide peer-to-peer learning opportunities, and increase leadership and teaching skills of senior nursing students. The peer mentorship role improves leadership and teaching skills, both important competencies for nursing students and potential faculty in the future. Peer mentoring fosters an enhanced understanding of our professional responsibility to engage in collegial teaching practice and mentorship, promoting nursing education leaders of the future. Within nursing education, the long-term benefits derived from a peer mentorship experience may be that these students seek mentors early in their nursing careers and foster collegial relationships that promote professional social development. Later in their careers, nurses who had positive peer-mentoring experiences as students may be more willing to take on a leadership role and serve as mentors to those entering the profession. Future research aimed at gathering data from a larger number of senior students, faculty members, and junior students from a variety of educational institutions over a longer period of time as they transition into professional practice would result in an increased amount of relevant and informative data and provide greater insight into the lived experience of those involved in a peer mentorship program. The longitudinal benefit of incorporating a peer mentorship course into the undergraduate curriculum is another potential area for future research. Once peer leaders graduate, further inquiry is needed into how they incorporate mentoring and leadership competencies into their professional practice roles. Another area for potential research may include exploration of peer leaders who seek out teaching and leadership roles and enroll in graduate studies.

\section{Acknowledgment}

This research was supported with funding from a Students' Union Quality Money Grant, University of Calgary, Calgary, AB, Canada.

\section{Disclosure}

The authors report no conflicts of interest in this work.

\section{References}

1. Canadian Institute for Health Information. Workforce Trends of Registered Nurses in Canada: The National Student and Faculty Survey of Canadian Schools of Nursing. Ottawa: Canadian Institute for Health Information; 2008.

2. Canadian Institute for Health Information. Regulated Nurses, 2012 - Summary Report. Ottawa: Canadian Institute for Health Information; 2012.

3. Canadian Nurses Association CAoSoN. Registered Nurse Education in Canada Statistics 2010-2011 - Registered Nurse Workforce, Canadian Production: Potential New Supply. Ottawa: Canadian Nurses Association CAoSoN; 2012.

4. Spouse J. Bridging theory and practice in the supervisory relationship: a sociocultural perspective. $J A d v$ Nurs. 2001;33(4):512.

5. Owens LD, Walden DJ. Peer instruction in the learning laboratory: a strategy to decrease student anxiety. J Nurs Educ. 2001;40(8):375-377.

6. Bensfield L, Solari-Twadell PA, Sommer S. The use of peer leadership to teach fundamental nursing skills. Nurse Educ. 2008;33(4): $155-158$

7. Kolb A, Kolb D. Learning styles and learning spaces: enhancing experiential learning in higher education. Acad Manage Learn Educ. 2005;4(2):193-212.

8. Knight CM. Evaluating a skills center: the acquisition of psychomotor skills in nursing - a review of the literature. Nurse Educ Today. 1998;18(6):441-447.

9. Aston L, Molassiotis A. Supervising and supporting student nurses in clinical placements: the peer support initiative. Nurse Educ Today. 2003;23(3):202-210. 
10. Roberts D. Learning in clinical practice: the importance of peers. Nurs Stand. 2008;23(12):35-41.

11. Hamid SL, VanHook J. First-year seminar peer leaders, programs and profiles. In: Hamid SL, editor. Peer Leadership: A Primer on Program Essentials. Monograph No 32. Columbia, SC: University of South Carolina, National Resource Center for the First-Year Experience and Students in Transition; 2001:75-86.

12. Carns AS, Carns MR, Wright J. Students as paraprofessionals in four-year colleges and universities: current practice compared to prior practices. J Coll Stud Dev. 1993;34(5):358-363.

13. Greenwood CR, Carta JJ, Hall RV. The use of peer tutoring strategies in classroom management and educational instruction. School Psych Rev. 1988;17(2):258-275.

14. Becker MK, Neuwirth JN. Educational innovations. Teaching strategy to maximize clinical experience with beginning nursing students. A clinical laboratory teaching assistant role was developed. J Nurs Educ. 2002;41(2):89-91.

15. Dennison S. Peer mentoring: untapped potential. J Nurs Educ. 2010;49(6):340-342.

16. Sweet S, Fusner S. Social integration of the advanced placement LPN: a peer mentoring program. Nurse Educ. 2008;33(5):202-205.

17. Scott ES. Peer-to-peer mentoring: teaching collegiality. Nurse Educ. 2005;30(2):52-56.

18. Sprengel AD, Job L. Reducing student anxiety by using clinical peer mentoring with beginning nursing students. Nurse Educ. 2004;29(6):246-250.

19. Grossman S, Valiga T. The New Leadership Challenge: Creating the Future of Nursing. 2nd ed. Philadelphia, PA: FA Davis; 2005.
20. Kolb DA. Experiential Learning: Experience as the Source of Learning and Development. New Jersey, NY: Prentice-Hall; 1984.

21. Husserl E. The Idea of Phenomenology. New York: Springer; 1964.

22. Dowling M. From Husserl to van Manen. A review of different phenomenological approaches. Int J Nurs Stud. 2007;44(1):131-142.

23. McConnell-Henry T, Chapman Y, Francis K. Husserl and Heidegger: exploring the disparity. Int J Nurs Pract. 2009;15(1):7-15.

24. Colaizzi PF. Psychological research as the phenomenologist views it. In: Valle RS, King M, editors. Existential Phenomenological Alternatives for Psychology. New York: Oxford University Press; 1978:58-62.

25. Gardiner W. Mentoring two student teachers: mentors' perceptions of peer placements. Teach Educ. 2010;21(3):233-246.

26. Sims-Giddens S, Helton C, Hope KL. Student peer mentoring in a community-based nursing clinical experience. Nurs Educ Perspect. 2010;31(1):23-27.

27. Kohler-Evans P. Co-teaching: how to make this marriage work in front of the kids. Education. 2006;127:260-264.

28. Chandler GE. Educational innovations. Growing nurse leaders: an undergraduate teaching assistant program. J Nurs Educ. 2005;44(12): $569-572$.

29. Tobin K, Roth W-M. Implementing coteaching and cogenerative dialoguing in urban science education. Sch Sci Math. 2005;105(6):313-322.

30. Lester JN, Evans KR. Instructors' experiences of collaboratively teaching: building something bigger. International Journal of Teaching and Learning in Higher Education. 2009;20:373-382.
Nursing: Research and Reviews

\section{Publish your work in this journal}

Nursing: Research and Reviews is an international, peer-reviewed, open access journal publishing original research, reports, reviews and commentaries on all aspects of nursing and patient care. These include patient education and counselling, ethics, management and organizational issues, diagnostics and prescribing, economics and

\section{Dovepress}

resource management, health outcomes, and improving patient safety in all settings. The manuscript management system is completely online and includes a very quick and fair peer-review system. Visit http://www.dovepress.com/testimonials.php to read real quotes from published authors. 